\title{
The circulation, the lung, and finger clubbing in hepatic cirrhosis
}

\author{
N. N. Stanley ${ }^{1}$ and D. J. Woodgate ${ }^{2}$ \\ From the Departments of Medicine and Cardiology, \\ The Royal Free Hospital, London W.C.I
}

Haemodynamic and respiratory data were obtained by gasometric methods in two groups of patients with hepatic cirrhosis, who were distinguishable by the presence or absence of finger clubbing. Cardiac index and venoarterial admixture were significantly higher in cases with clubbing; these findings are discussed. However, levels of venoarterial admixture were normal in four with clubbing, which suggests that increased right-to-left shunt flow is not an essential factor in the pathogenesis of clubbing in liver disease.

Finger clubbing is most often seen in diseases of the lungs or heart, but it is also a common finding in hepatic cirrhosis. The pathogenesis of clubbing is not fully understood, but various studies (Mendlowitz, 1938; Charr and Swenson, 1946; Lovell, 1950; Wilson, 1952) have shown that it may be a consequence of digital vasodilatation. Furthermore, Hall (1959) suggested that venoarterial admixture might be responsible for clubbing in certain cardiopulmonary diseases; he proposed that a vasodilator substance normally detoxicated in the pulmonary capillary bed could thereby enter the systemic circulation and cause the associated digital vascular changes. Since venoarterial admixture in cirrhosis may result from both intrapulmonary arteriovenous (Rydell and Hoffbauer, I956) or porta-pulmonary anastomoses (Calabresi and Abelmann, 1957), and peripheral vasodilatation may be widespread giving an increased cardiac output (Kowalski and Abelmann, 1953), it has seemed possible that this lung bypass mechanism might account for clubbing in liver disease (Stein and Stein, 196I; Bashour, McConnell, and Miller, 1967). Previous evidence concerning the association of clubbing and increased venoarterial admixture in cirrhosis has been conflicting: cases with cyanosis invariably have clubbing, but the converse has not been true and patients with clubbing may have normal arterial Received 27 August 1970.

1 Present address: Pulmonary Diseases Section, Hospital of the University of Pennsylvania, Philadelphia, U.S.A.

2 Present address: St. Andrew's Hospital, Billericay, Essex. saturation (Abelmann et al., I96I ; Shaldon et al., 1961). However, venoarterial admixture must be fairly large to reduce arterial saturation significantly (Georg et al., 1960), especially in cirrhosis when increased peripheral blood flow is accompanied by a small arteriovenous oxygen difference.

The purpose of our study was to establish the interrelation of arterial hypoxaemia, venoarterial admixture, hyperkinetic circulation, and finger clubbing in chronic liver disease.

\section{Subjects and methods}

We investigated 24 volunteer patients with hepatic cirrhosis, 12 with and 12 without clubbing. No case was severely decompensated; none had ascites or more than mild encephalopathy. We deliberately selected cases, where necessary, to equalize the mean serum albumin levels in the two groups for the purpose of keeping the groups closely matched for liver failure. For comparison we assessed respiratory function in 12 healthy control subjects. All patients were studied at rest, supine, without sedation, and in the postabsorptive state.

A fine nylon microcatheter (Portex) was flowguided to the pulmonary artery from the right antecubital vein using a pressure transducer and oscillographic recorder (Sanborn). A polyethylene cannula was placed in the right brachial artery. After an adequate settling down period, expired gas was collected for 3 minutes in a Douglas bag while the patient breathed ambient air using a mouthpiece, noseclip, and one-way valve. During this time mixed venous and arterial blood samples were drawn into heparinized syringes. Next the patient breathed 99.5 per cent oxygen for at least I5 minutes after which further blood samples were taken. $\mathrm{Po}_{2}, \mathrm{PcO}_{2}$, and $\mathrm{pH}$ of blood samples were measured by Radiometer electrodes. The 
expired air was analysed for $\mathrm{O}_{2}$ and $\mathrm{CO}_{2}$ by the Haldane apparatus. Alveolar $\mathrm{PO}_{2}$ was calculated by the alveolar air equation, assuming that arterial and alveolar $\mathrm{PCO}_{2}$ were equal. The alveolar-arterial $\mathrm{Po}_{2}$ difference $\left(\mathrm{A}-\mathrm{aDo}_{2}\right)$ was obtained by subtraction. Oxygen contents of blood samples were calculated from their oxygen tensions using the data of Kelman and Nunn (1966) to determine oxygen saturation and the data of Christoforides and Hedley-Whyte (1969) to determine dissolved oxygen. Oxygen consumption was estimated from the composition of expired air, which allowed cardiac output ( $Q t)$ to be derived by the Fick principle. Venoarterial admixture (Qva) was calculated from the measurements obtained during oxygen breathing using the standard shunt formula:

$$
\frac{\mathrm{Q} v a}{\mathrm{Q} t}=\frac{\mathrm{Cc}, \mathrm{O}_{2}-\mathrm{CA}_{,} \mathrm{O}_{2}}{\mathrm{C}, \mathrm{O}_{2}-\mathrm{C} \overline{\mathrm{V}}, \mathrm{O}_{2}}
$$

Where $\mathrm{C}, \mathrm{O}_{2}, \mathrm{CA}_{\mathrm{A}} \mathrm{O}_{2}$, and $\mathrm{C} \overline{\mathrm{V}}, \mathrm{O}_{2}$ are the oxygen contents of end-pulmonary capillary, arterial, and mixed venous blood respectively; oxygen equilibration between end-capillary blood and alveolar gas was assumed to be complete. In our control subjects mixed venous blood was not sampled, but its oxygen content was assumed to be 4.5 volumes per cent less than arterial blood.

\section{Results}

The clinical and physiological findings are shown in the Table. Mild arterial hypoxaemia was common in the patients with cirrhosis. In the group with clubbing the mean arterial $\mathrm{PO}_{2}$ was slightly lower and the mean $\mathrm{A}-\mathrm{aDO}_{2}$ was slightly higher than in the group without clubbing, but neither difference was significant $(\mathbf{P}>0.5$, and $0.1<P<0.2)$. Cardiac indices (Fig. I) were higher $(P=0.00 r)$ and arteriovenous $\mathrm{O}_{2}$ differences were lower $(0.00 \mathrm{I}<\mathrm{P}<0.005)$ in the patients with clubbing compared with those without clubbing. Venoarterial admixture was higher in cases with clubbing than in those without clubbing $(0.01<\mathrm{P}<0.05)$, but normal levels were found in several patients from each group (Fig. 2). A positive correlation was obtained between the increases of cardiac index and venoarterial admixture (Fig. 3). This was significant when the results of both groups of patients were pooled $(r=0.74, P<0.001)$. When taken as separate populations this correlation was still significant in the cases with clubbing $(\mathrm{r}=0.66,0.0 \mathrm{I}<\mathrm{P}<0.05)$ but was not significant in the group without clubbing $(r=0.49, P=0.1)$.

\section{Discussion}

Our results confirm an earlier impression that the hyperdynamic circulation of hepatic cirrhosis is often pronounced in patients with finger clubbing (Bashour et al., 1967). The similar levels of arterial $\mathrm{O}_{2}$ tensions in our

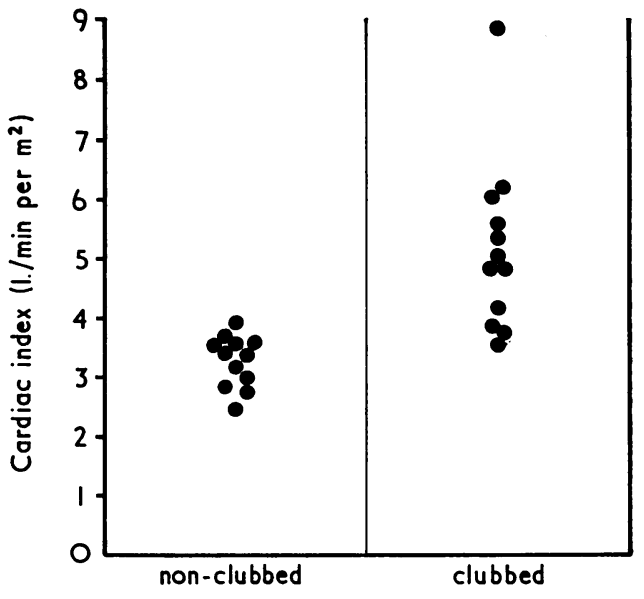

FIG. I Levels of cardiac index in cases of hepatic cirrhosis with and without clubbing.

patients with and without clubbing also agree with previous reports in which no correlation was found between clubbing and arterial unsaturation in hepatic cirrhosis (Abelmann et al., 196I; Shaldon et al., 196I). Thus it is interesting that venoarterial admixture was significantly higher in the cases with clubbing compared to those without clubbing. This paradox was largely due to the smaller arteriovenous $\mathrm{O}_{2}$ differences in the patients with clubbing, which had lessened the reduction of their arterial $\mathrm{O}_{2}$ tensions by a given amount of venoarterial admixture.

The regional circulatory disturbances in cirrhosis are complex, but it would be sur-

FIG. 2 Levels of venoarterial admixture in normal subjects and cases of hepatic cirrhosis with and without clubbing.

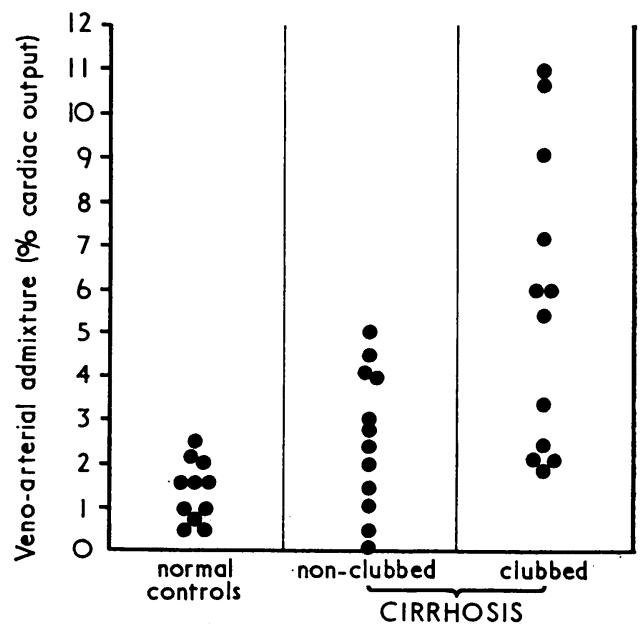


prising if some were not interrelated in their causation. A characteristic microvascular change at many sites is the opening of arteriovenous anastomoses, but the vasodilator mechanism for this is obscure, and multiple factors may be involved. The presence of these anastomoses in the pulmonary circulation is well established as the chief cause of the raised venoarterial admixture in liver disease. It has also been suggested that increased anastomotic flow in the peripheral and digital circulations, respectively, may account for the high cardiac output in cirrhosis (Silverstein, 1956) and the increased digital blood flow associated with clubbing (Lovell, 1950; Wilson, 1952). However, it remains conjectural whether or not the correlation found between clubbing, increased venoarterial admixture, and hyperkinetic circulation in our patients was due to a common response in their digital, pulmonary,

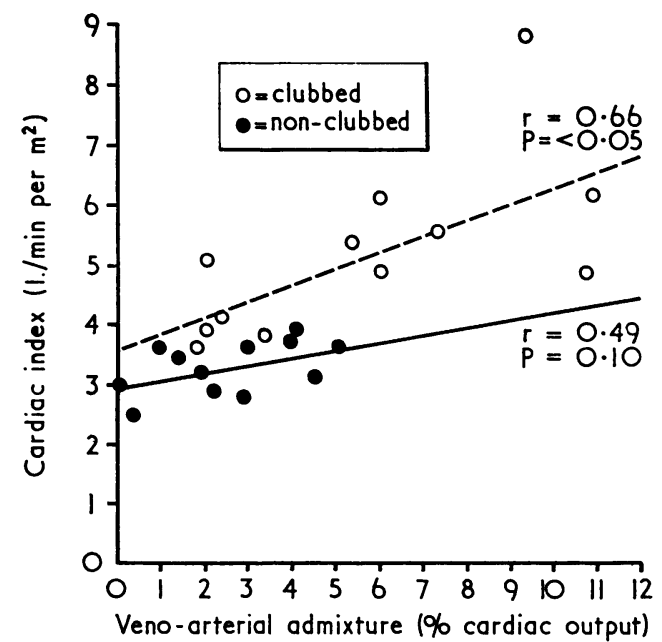

FIG. 3 Relation of cardiac index to venoarterial admixture in cases of hepatic cirrhosis.

TABLE Clinical and physiological data in cases of hepatic cirrhosis with and without finger clubbing, and physiological data in healthy control subjects

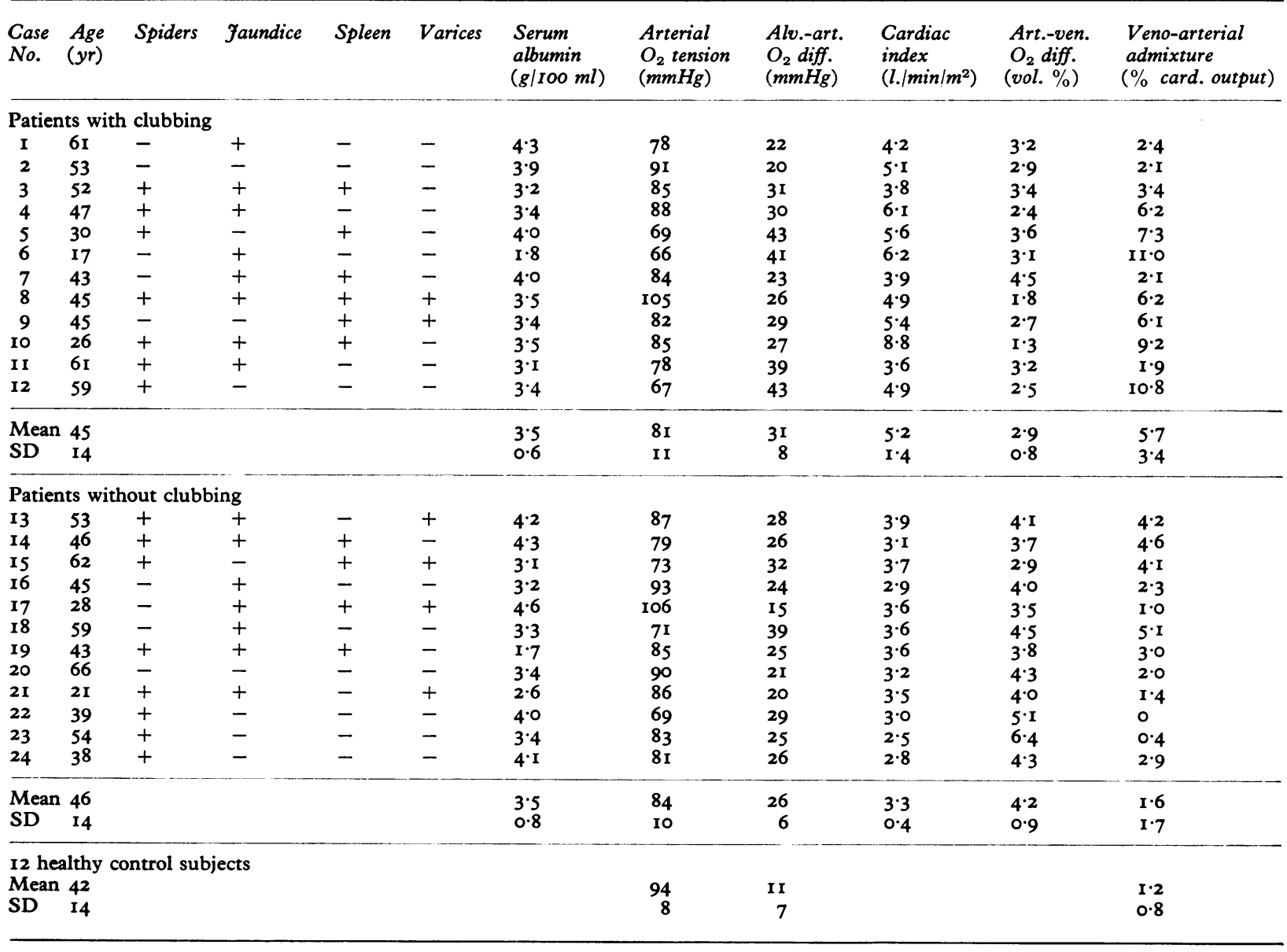


and peripheral vascular beds to a single vasodilator mechanism.

The estimated levels of venoarterial admixture were normal in four patients with clubbing (Cases I, 2, 7, and II), but this finding requires further comment. Our methods tend to underestimate the total right-to-left shunt flow in cases with functioning porta-pulmonary anastomoses; the oxygen content of portal venous blood is high (Bradley et al., 1953) and in our calculations we assumed that pulmonary arterial blood and blood traversing all right-to-left shunts were equally saturated. This assumption seems justifiable as flow through these portapulmonary anastomoses is comparatively small and has been found negligible in cases without prominent signs of a portal-systemic collateral circulation (Nakamura et al., 1965). In particular, our four patients with clubbing and apparently normal levels of venoarterial admixture had no clinical or radiological evidence of such a collateral circulation, which makes a serious underestimate of their venoarterial admixture unlikely. Thus an increased right-to-left shunt flow does not seem essential for the development of clubbing in hepatic cirrhosis.

We wish to thank Professor Sheila Sherlock for permission to study patients under her care and Dr. Frances Gardner for allowing us to use the equipment of the Department of Cardiology. Also we gratefully acknowledge the skilled technical and nursing assistance given by $\mathrm{Mr}$ Donald Wagstaff, Mrs Carol Shaw, and Miss Harriet Copperman.

\section{References}

Abelmann, W. H., Kramer, G. E., Verstraeten, J. M., Gravallese, M. A., and McNeely, W. F. (I96r). Cirrhosis of the liver and decreased arterial oxygen saturation. Archives of Internal Medicine, 108, 34.

Bashour, F. A., McConnell, T., and Miller, W. F. (1967). Circulatory and respiratory changes in patients with Laennec's cirrhosis of the liver. American Heart fournal, 74, 569.

Bradley, S. E., Smythe, C. M., Fitzpatrick, H. F., and Blakemore, A. H. (1953). Effect of a portacaval shunt on estimated hepatic blood flow and oxygen uptake in cirrhosis. Fournal of Clinical Investigation, 32, 526.

Calabresi, P., and Abelmann, W. H. (1957). Portocaval and porto-pulmonary anastomoses in Laennec's cirrhosis and in heart failure. Fournal of Clinical Investigation, 36, 1257.

Charr, R., and Swenson, P. C. (1946). Clubbed fingers. American fournal of Roentgenology, 55, 325.

Christoforides, C., and Hedley-Whyte, J. (I969). Effect of temperature and hemoglobin concentration on solubility of $\mathrm{O}_{2}$ in blood. Fournal of Applied Physiology, 27, 592.

Georg, J., Mellemgaard, K., Tygstrup, N., and Winkler, K. (1960). Veno-arterial shunts in cirrhosis of the liver. Lancet, $1,852$.

Hall, G. H. (1959). The cause of digital clubbing. Testing a new hypothesis. Lancet, $\mathbf{r}, 750$.

Kelman, G. R., and Nunn, J. F. (1966). Nomograms for correction of blood $\mathrm{Po}_{2}, \mathrm{PcO}_{2}, \mathrm{pH}$, and base excess for time and temperature. Fournal of Applied Physiology, 21, 1484.

Kowalski, H. J., and Abelmann, W. H. (1953). The cardiac output at rest in Laennec's cirrhosis. fournal of Clinical Investigation, 32, 1025.

Lovell, R. R. H. (1950). Observations on the structure of clubbed fingers. Clinical Science, 9, 299.

Mendlowitz, M. (1938). Some observations on clubbed fingers. Clinical Science, 3, 387.

Nakamura, T., Nakamura, S., Tazawa, T., Abe, S., Arkawa, T., and Tokita, K. (1965). Measurement of blood flow through portopulmonary anastomosis in portal hypertension. Fournal of Laboratory and Clinical Medicine, 65, I14.

Rydell, R., and Hoffbauer, F. W. (1956). Multiple pulmonary arteriovenous fistulas in juvenile cirrhosis. American fournal of Medicine, 21, 450.

Shaldon, S., Caesar, J., Chiandussi, L., Williams, H. S., Sheville, E., and Sherlock, S. (I96r). The demonstration of porta-pulmonary anastomoses in portal cirrhosis with the use of radioactive krypton $\left(\mathrm{Kr}^{85}\right)$. New England Fournal of Medicine, 265, 410.

Silverstein, E. (1956). Peripheral venous oxygen saturation in patients with and without liver disease. Fournal of Laboratory of Clinical Medicine, 47, 513 .

Stein, H., and Stein, S. (196r). Digital clubbing in cirrhosis of the liver. Lancet, 2, 999.

Wilson, G. M. (1952). Local circulatory changes associated with clubbing of the fingers and toes. Quarterly fournal of Medicine, 21, 201. 